\title{
Research on Project-driven Human Resource Planning Model
}

\author{
Jiayi Yao ${ }^{1}, \mathrm{Xi} \mathrm{Deng}^{1}$ and Hui Zhu ${ }^{1}$ \\ ${ }^{1}$ School of Economics and Management \\ Beijing Jiaotong University \\ No.3 Shang Yuan Cun \\ Hai Dian District \\ Beijing, China 100044 \\ jyyao@bjtu.edu.cn
}

\begin{abstract}
With the increasing to IT Outsourcing Managed Service, talent dispatch agencies spring up as time goes by. But fiercer competition has been brought here as the talent dispatch agency quickly develops and the market share tenses. The large cost imposed by HR management of talent dispatch agency stands a higher proportion in capital, so it is fatal to reduce HR cost for the talent dispatch agency. This article based on this background combines the study for existing workflow in talent dispatch and establishes a multiple HR planning model. This model provides a solution in how to dispatch when, considering the balance between recruitment and the extra working hours, and conducts the way of personnel dispatch for an optimizing choice within the dispatch planning so as to maximize the benefit for the dispatching enterprises. Additionally, this article also generates the recruitment planning and the dispatch planning through the calculation of an example via computer software as the design implication of work.
\end{abstract}

\section{Background}

Originated in United States, developed and implemented in the Europe, America, Japan and so on, talent dispatch industry has been widely promoted in many countries. In the middle and late 1990s, talent dispatch industry entering China and had rapidly developed in recent years. There are some inevitability reasons by the demand of Market economy of the importing of talent dispatch industry in China. With the talent dispatch industry gradually extended, some talent dispatch agency signed a contract with the employing companies, professionally being outsourced the business of employing companies such as recruitment and selection, training \& development and so. With the help of talent dispatching, these employing enterprises become more flexible of the rapidly changing and effectively reduce their costs in human resource. Now in 21 st century, by the growing and deploying of IT industry, companies realized that lacking of IT recruits makes they short in competition and therefore a requirement of more IT recruits come to the ground. What the manager of talent dispatch agencies concern is that, described in terms of economics, the contradiction between "the limited resources" and "the infinite desires". In specification, it is that using the available recruits to satisfy projects which are for dispatching as more as they can. So the manager should properly make plans. However, the costs of an IT recruits is relatively expansive because of their excellent IT skills and that makes an IT talent dispatch agency suffering a large expenditure in human resource. It is a great challenge to lower this expenditure.

As far as this article concerned, there are seldom articles about this issue, which makes the improper planning before deploying the dispatching and course such a most common problem like that in order to fulfill a project in time, an enterprise has to recruit extra employees beyond 
the estimate of its human resource planning or be force to work in extra time. If such a situation had been planned properly before a dispatching being deployed, there would be lesser expensively recruiting outcomes or such low morale caused by an overtime. Therefore, the model of human resource planning of talent dispatch agencies proposed by this article will be a practical significance.

There is an assumption in this article: assuming that all talent dispatching projects have been reached a consensus between employing companies and talent dispatch agencies so that there are no cases of rejections of a dispatching project, this article proposes the "project-driven human resource planning" model.

\section{Ideas of Designing this Model}

The HR planning of talent dispatch agency is not as equal as those common HR planning. Generally speaking, HR planning concerns the trade-off between its human resource demand and supply of a conventional job position, which is defined in job analysis. But in the HR planning in those talent dispatch agencies, the demand comes along with the employing company's demand or the result calculated by the demand of its recruits of a specific project. The HR planning in talent dispatch agency is easier to qualify relatively than the rest kind of companies. Although there are some researches in this field in foreign countries, such as People soft of Oracle, which is able to outsourcing the management of dispatch assignments. But above all, those researches emphases those contents of everyday business, for example, the labor relationship in HR management, the information management of employees, legal relations, etc. Meanwhile, few researches mentioned the model, which could make efforts to cut the talent dispatch agency's expenses and improve the profits, for the HR planning of talent dispatch. And the model in this article emerges as the requirement.

According to author's investigate and survey, the workflow of a talent dispatch agent becomes clear, that before a talent dispatch agent and an employing company (Party A) signing of cooperate of one or many projects, a project manager of talent dispatch agent will be sent to work along with the Party A company for a period, usually two weeks to a month, to generate a report. This report may consists of the aspects of what kind of employee required in this project, how many recruits required in each kind, the estimated time the project required to finish, the reward or the revenue of this project and so on. Based on this report, the talent dispatch agency draws the plan that construct the architecture of the team to meet the demand, make decision whether recruitment is needed. It will decide how to dispatch the proper staff if there are sufficient staffs to meet the need, or alternatively conduct recruitment when there is insufficient staff. In China, many talent dispatch agencies have already implemented the "on-demand recruitment" system, but most of these so-called "on-demand recruitment" didn't have a scientific basis, that is, that how many the recruits hiring and what kind of recruits hiring will accomplish the project in time while making the spend as little as possible. As the consequence, this article proposed an integer liner programming model to solve this issue.

\section{Details of Model}

The HR planning model of IT talent dispatch agencies consists of three inputs: the Project Plan, the List of Human Structure, and the Human Inventory Record. With these three inputs calculating in the model, two outputs will be drawn, that is, the Plan of Recruitment and the Plan of Dispatching, as the Figure 1 shows below: 


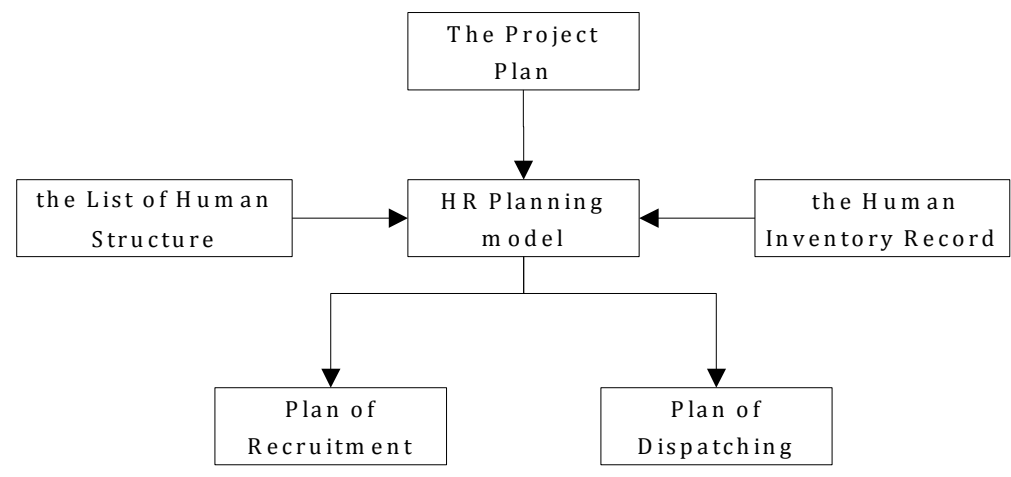

Figure 1. The Workflow of HR Planning Model

\subsection{The HR Planning Model in Single Project}

The most ultimate purpose of a talent dispatch agency is, in common, "to make money". As we know, only with its cash flow gets maintained, the talent dispatch agency will survive and then has the ability to compete severely among the others. According to the survey, this article considers that the revenue comes with the project fees paid by the Party A, and the costs will be the labor costs, recruitment costs, and some other costs. The model in this article defines three kind of costs as below:

- Fixed Cost, which refers to those costs that remains unchanged along with the number of staffs, like office costs.

- Variable Cost, which refers to those costs that associate with the numbers of the staff to be dispatched or the time. It is divided into two kinds of Variable Cost: Variable Cost A refers that this cost will differ from the job, such as the wage of the dispatch employees or their overtime pay, while Variable Cost B not, just like those business trip fee. Obviously, Both Variable Cost $\mathrm{A}$ and Variable Cost B will increase with the time and the number of employees.

- Recruitment Cost, which refers to the average recruitment and selection of a qualified dispatch employee that cost, which will include the cost of recruitment, training costs and some other related expenses. Recruitment Cost is a fixed cost, a one-time cost and does not change or increase over time.

Undoubtedly, the talent dispatch agency's eventually want is the smallest of these costs and the greatest profits. Let the Project Revenues to R, Total Working Hour to Q, Fixed Costs to C, Variable Costs 1 to $\mathrm{W}$, Variable Costs 2 to M, the frequency of Variable Costs, like staff salaries monthly payment, to $\mathrm{D}$ and the staff work duration to $t$ working hours. Thus, without considering the recruitment and companies are now able to meet the needs of the project staff. Let the project requires i kinds of job, each job requires $x_{i}$ personal. So the objective is shown below:

$$
\min _{x} C+\sum_{i=1}^{n} D_{i} x_{i}\left(W_{i}+M\right)
$$

And there are two constraints. The cost must be less than the revenue while the total working hour must be satisfied: 


$$
\begin{aligned}
& C+\sum_{i=1}^{n} D_{i} x_{i}\left(W_{i}+M\right) \leq R \\
& \max _{i}\left\{\left(D_{i} x_{i}\right) \cdot t\right\} \geq Q \quad \forall i
\end{aligned}
$$

\subsection{The HR Planning Model in Multi-Projects}

The talent dispatch agency always comes up with multiple projects. When facing a multi-projects problem, the talent dispatch agency needs to consider that the objective of profit maximization besides the trade-off of those multi-projects. Thus this article establishes the HR planning model in multi-projects which using the multiple objective program to maximize the effectiveness. The talent dispatch agency usually set high priority to those which are high profits, paying fast, low-risk, and relatively high in urgency. These factors above can be defined representing as a "weight". Thus let the Weight to $\lambda$ :

$$
\lambda_{t}>0(t=1,2,3 \cdots)
$$

The model assumes that all factors of single projects weight value as:

$$
\lambda_{t}=f(\varepsilon)
$$

Based on the assumptions above, the benefit of number $t$ project which equals to the revenue $\mathrm{R}$ minus the project's cost. Let the benefit to $\mathrm{NP}_{\mathrm{t}}$, and the weighted benefit should be $\mathrm{P}_{\mathrm{t}}$ as:

$$
P t=\lambda_{t} * N P t
$$

The NPt is:

$$
N P t=R t-\left(C+\sum_{i=1}^{n} D_{i} x_{i}\left(W_{i}+M\right)\right)
$$

The HR planning model in multi-projects, therefore, is essentially based on the weight of multiple projects objective program model. That is:

$$
\begin{aligned}
& \max _{x} Z=\sum_{i=1}^{n} \lambda_{t} * N P t \\
& {\left[C+\sum_{i=1}^{n} D_{i} x_{i}\left(W_{i}+M\right)\right] \leq R_{t}} \\
& {\left[\max _{i}\left\{\left(D_{i} x_{i}\right) \cdot t\right\}\right] \geq Q_{t}} \\
& \forall i, t
\end{aligned}
$$

The $t$ refers to the $t^{\text {th }}$ project, and the $i$ refers to the $i^{\text {th }}$ kind of project in the $t^{\text {th }}$ s.

However, there won't be such a situation that every project comes at a same time in reality. Instead, those projects will come at different times so that some of the employees can be dispatched to the next project while their duty in their first project is complete. Based on this situation, this article throws an idea to solve this problem that the optimization is to minimize the total idle time of the dispatch employees. And it will be discussed in Section 3.6. 


\subsection{The Details of the Model}

\subsubsection{Including Recruitment}

When the talents dispatch agency lack of labors to meet the need of the project, recruitment shall be conduct and it makes a Recruitment Cost. According to the model above, let the average recruitment cost per employee of the $i^{\text {th }}$ kind of job to $U_{i}$, let a binary variable to $y_{i}$, which refers:

$$
y_{i}=\left\{\begin{array}{lll}
0 \text { no } & \text { need } & \operatorname{Re} \text { cruitment } \\
1 & \text { need } & \operatorname{Re} \text { cruitment }
\end{array}\right.
$$

Let the inventory of the $\mathrm{i}^{\text {th }}$ job's kind of dispatch employees to $\mathrm{x}_{0 \mathrm{i}}$. It's obvious that when the number of people that project needed is greater than the inventory stores, which means when $x_{i}$ that mentioned in the section 3.1 is greater than $\mathrm{x}_{0 \mathrm{i}}$, recruitment shall be conducted so that it generated the recruitment cost at on these $\mathrm{x}_{\mathrm{i}}-\mathrm{x}_{0 \mathrm{i}}$ people. Otherwise when $\mathrm{x}_{\mathrm{i}}$ is less than $\mathrm{x}_{0 \mathrm{i}}$ the recruitment is not needed so that there will generated no recruitment cost. Let the weight of $t^{\text {th }}$ project to $\lambda_{\mathrm{t}}$. Hence the Objective function is:

$$
\min _{x, y} \sum_{i} \lambda_{,} *\left[C+\sum_{i=1}^{n} D_{i} x_{i}\left(W_{i}+M\right) \leq R\right]+\sum_{i=1}^{n} y_{i} U_{i}\left(x_{i}-x_{0 i}\right)
$$

It is similar that some new constraints need to be added. Recruitment should be conducted when insufficient people in the inventory while it is not when there is a surplus. To make sure the model is convergence, the constraint function shall be:

$$
\left(y_{i}-\varepsilon\right)\left(x_{i}-x_{0 i}-\varepsilon\right) \geq 0 \quad \varepsilon \in[0,1], \quad i \in[1, n] \& i \text { is Integer }
$$

This constraint means to make sure when the latter item of constraint function is less than zero, that is, a surplus of people in inventory, the $y_{i}$ can only be zero in order to keep the left side of function being positive, which means no need of recruitment. Analogously, when the latter item is greater than zero, which means an insufficient of employee, the $\mathrm{y}_{\mathrm{i}}$ can only be one. To make sure the model being convergence, this model introduces $\varepsilon$ which is a variable between zero and one. The article discovered that without this $\varepsilon$ the computer software calculated not convergence when $\mathrm{x}_{\mathrm{i}}$ equals to $\mathrm{x}_{0 \mathrm{i}}$, which means the inventory meet the need of the project's wants be just like seem, the $y_{i}$ can be either zero or one, and cause a biased situation.

\subsubsection{Including Extra Work-Time}

Extra work-time in talent dispatch, which usually occasions in overtime, brings the dispatch agency an alternative choice in making their HR planning. The decision of overtime, which additionally increases the work time per employee, can reduce the total number of employees of a project, as well as the number in recruitment. However, as the saying in Chinese goes "There is no free lunch in the world", it causes the additional pay in extra work-time situations. Hence the decision-maker should weigh between these two costs.

In case of the model shows above, Let the over-time which an individual work in a pay period of the $\mathrm{i}^{\text {th }}$ kind of job to $(\mathrm{ot})_{\mathrm{i}}$. So the overtime pay is a function of $(\mathrm{ot})_{\mathrm{i}}$. This function will be different from company to company. Let the overtime pay function to $\mathrm{f}_{\mathrm{i}}(\mathrm{ot})$ as it is shown below: 


$$
\min _{x, y, o t} \lambda_{i} *\left[C+\sum_{i=1}^{n} D_{i} x_{i}\left(W_{i}+\mathrm{f}_{\mathrm{i}}(\mathrm{ot})+M\right) \leq R\right]+\sum_{i=1}^{n} y_{i} U_{i}\left(x_{i}-x_{0 i}\right)
$$

And the work time constraint changes to:

$$
\max \left\{\left(D_{i} x_{i}\right) \cdot(t+o t)\right\} \geq Q \quad i \in[1, n]
$$

This model also adds a limit of the duration of over-time. Let it to $\mathrm{OT}_{\mathrm{i}}$ and the limitation of overtime constraint should be:

$O t i \leq O T i$

\subsection{The Whole Model}

Putting the model together, the HR planning model of talent dispatch agency is shown as:

$$
\begin{aligned}
& \max _{x, y, 0 t} \sum_{i} \lambda_{i} * N P t-\sum_{i=1}^{n} y_{i} U_{i}\left(x_{i}-x_{0 i}\right) \\
& N P t=R t-\left[C+\sum_{i=1}^{n} D_{i} x_{i}\left(W_{i}+\mathrm{f}_{\mathrm{i}}(\mathrm{ot})+M\right)\right],
\end{aligned}
$$

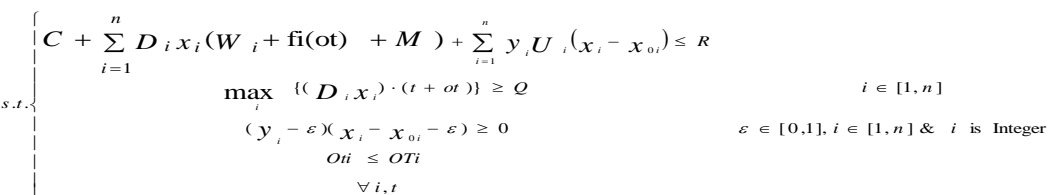

\subsection{Design Implication of Work}

Assumed there is a project and its inputs shows as the Table 1.

Table 1. The Project Inputs

\begin{tabular}{|l|l|l|l|l|l|l|l|l|l|l|}
\hline $\begin{array}{l}\text { kind } \\
\text { of job }\end{array}$ & $\begin{array}{l}\text { Variable } \\
\text { Cost 1:W }\end{array}$ & $\begin{array}{l}\text { Variable } \\
\text { Cost 2:M }\end{array}$ & $\begin{array}{l}\text { Recruitmen } \\
\mathrm{t} \text { Cost 1:W }\end{array}$ & $\begin{array}{l}\text { Inventory } \\
\mathrm{X}_{0}\end{array}$ & $\mathrm{f}(\mathrm{ot})$ & $\begin{array}{l}\text { Limitation } \\
\text { of OT }\end{array}$ & $\begin{array}{l}\text { Total work } \\
\text { time:Q }\end{array}$ & $\begin{array}{l}\text { Monthly } \\
\text { working } \\
\text { house:t }\end{array}$ & $\begin{array}{l}\text { Fixed } \\
\text { Cost:C }\end{array}$ & $\begin{array}{l}\text { Revenue:R } \\
\text { Accom } \\
\text { plish in } \\
\text { (month) }\end{array}$ \\
\hline A & 10000 & 2000 & 3000 & 10 & $50 \%$ & 80 & 2400 & 160 & 20000 & 1000000 \\
\hline B & 20000 & 2000 & 3000 & 2 & $50 \%$ & 80 & 1200 & 160 & 3 \\
\hline
\end{tabular}

The result of calculation is convergence and the max benefit is 674000 . The $\mathrm{y}_{\mathrm{i}} \mathrm{s}$ all being end with zero indicates that the entire job do not need recruitment. $\mathrm{x}_{1}$ is 4 which means the dispatch agency should send 4 people of job A. Likewise, the agency should send 2 people of job B. The $(o t)_{i}$ is are 40 both job $A$ and job $B$ which refers both job $A$ and job B needs do a 40-hours-overtime per person per month.

Table 2. The Result of Model

\begin{tabular}{|l|l|l|l|l|}
\hline \multicolumn{2}{|l|}{ Object (max) } \\
\hline & item & Description & $\begin{array}{l}\text { Initial } \\
\text { Value }\end{array}$ & $\begin{array}{l}\text { Optimized } \\
\text { Value }\end{array}$ \\
\hline & $\mathrm{z}$ & The max benefit & 980000 & 674000 \\
\hline \multicolumn{2}{|l}{ Variables } \\
\hline
\end{tabular}




\begin{tabular}{|l|l|l|l|}
\hline item & Description & $\begin{array}{l}\text { Initial } \\
\text { Value }\end{array}$ & $\begin{array}{l}\text { Optimized } \\
\text { Value }\end{array}$ \\
\hline $\mathrm{y}_{1}$ & Job A needs recruitment? & 0 & 0 \\
\hline $\mathrm{x}_{1}$ & Number of labor dispatch in job A & 0 & 4 \\
\hline $\mathrm{ot}_{1}$ & $\begin{array}{l}\text { Overtime per person per month in } \\
\text { job A }\end{array}$ & 0 & 40 \\
\hline $\mathrm{y}_{2}$ & Job B needs recruitment? & 0 & 0 \\
\hline $\mathrm{x}_{2}$ & Number of labor dispatch in job B & 0 & 2 \\
\hline $\mathrm{ot}_{2}$ & $\begin{array}{l}\text { Overtime per person per month in } \\
\text { job B }\end{array}$ & 0 & 40 \\
\hline
\end{tabular}

The result of calculation is convergence and the max benefit is 674000 . The yis all being end with zero indicates that the entire job do not need recruitment. $x_{1}$ is 4 which means the dispatch agency should send 4 people of job A. Likewise, the agency should send 2 people of job B. The $(\mathrm{ot})_{\mathrm{i}}$ is are 40 both job A and job B which refers both job A and job B needs do a 40-hours-overtime per person per month.

\subsection{Dispatch Planning Model}

The decision-maker of talent dispatch agencies decides whom to be dispatched after generating the calculation and optimization as the former sections show. However, the sections above show and calculate only the number of dispatch employees of each job kind. And the planning model is necessary to elaborate the dispatch planning to the decision-maker. That is because employees differ from each other, some are good with skills while some are not as good as that. Moreover, some employees are generalists that capable with lot kinds of jobs and he can only be dispatched to one job. And some employees, like pregnant women, cannot guarantee the working hours. With such complex cases the talent dispatch agency should make an optimization of dispatching.

This article proposes another weight value to define the merits of an employee. The agency will always dispatch the employees with good merits rather than them of not so good. There are many ways to quantify the skills of an employee as a weight value and it is not an aspect of this article. Let the $\mathrm{k}^{\text {th }}$ employee's skill vector to $\varphi_{k}$ that:

$$
\varphi_{k}=\left(a_{i}, a_{2}, \cdots, a_{i}\right) \quad i \in[1, n]
$$

For example, suppose the full point is 5, and an employee of four skills can be described as:

$$
\varphi_{k}=\{\text { Skill NO.1:4, Skill NO.2:5, Skill NO.3:2, Skill NO.4:5 }\}
$$

And a project will need some employees with certain kind of skills. This article proposes a Skill Weight Value of a Job (short as SWVJ). Let the SWVJ of job A to $\mu_{a}$ that:

$$
\mu_{a}=\left(\theta_{1}, \theta_{2}, \cdots, \theta_{i}\right) \quad i \in[1, n]
$$


Of which:

$$
\sum_{i} \theta=1
$$

The meaning of $\mu_{a}$ is that the significance of skill i in job A is $\theta_{i}$. Assumed that the SWVJ of job $A$ is that:

$$
\mu_{a}=\{\text { Skill NO.1:0.3, Skill NO.2:0.5, Skill NO.3:0.2, Skill NO.4:0 }\}
$$

In this case, the SWVJ reflects intuitively a certain type of work for the employees of the importance to the job. And the Weighed Skill of this employee s can be stated that:

$$
S=\varphi \cdot \mu=a_{1} \theta_{1}+a_{2} \theta_{2}+\cdots+a_{i} \theta_{i} \quad i \in[1, n]
$$

And the result of calculation is:

$$
S=\varphi \cdot \mu=4 \times 0.3+5 \times 0.5+2 \times 0.2+5 \times 0=4.1
$$

Well, according to the above, this model can find all that the capability between $\mathrm{j}^{\text {th }}$ employee and the $\mathrm{i}^{\text {th }}$ job. Let that to $\mathrm{s}_{\mathrm{ij}}$. And all the capability in $\mathrm{m}^{*} \mathrm{n}$ array can be expressed as:

$$
\begin{array}{cccccc}
S_{11} & S_{12} & \cdots & S_{1 j} & \cdots & S_{1 n} \\
S_{21} & S_{22} & \cdots & S_{2 j} & \cdots & S_{2 n} \\
\cdots & \cdots & \cdots & \cdots & \cdots & \cdots \\
S_{i 1} & S_{i 2} & \cdots & S_{i j} & \cdots & S_{i n} \\
\cdots & \cdots & \cdots & \cdots & \cdots & \cdots \\
S_{m 1} & S_{m 2} & \cdots & S_{m j} & \cdots & S_{m n}
\end{array}
$$

In the dispatch planning model of this article, it is assumed that each person can only do one job and cannot wear two hats in the premise. Let the employees' demand of Job i to $x_{i}$, let a certain person to do the job to $\mathrm{j}$ let a $0-1$ variable to $z_{\mathrm{ij}}$, which means when $z_{\mathrm{ij}}$ equals 0 person $\mathrm{j}$ will not be dispatched to job I and when it equals to 1 the dispatch will happen. So the dispatch planning optimization model is that: 


$$
\begin{aligned}
& \max _{Z i j} \sum_{i} \sum_{j} S i j Z i j \\
& \text { s.t. } \\
& \sum_{i} Z i j=1 \\
& \sum_{i} Z i j=x_{i}
\end{aligned}
$$

Remember the situation of multiple projects planning mentioned in section 3.2. It is envisage of modeling in optimization that the objective function is to minimize the idle time of all the employees rather than they be idle (idle employees because of affirmative no value making) to reach the optimum and the constraint will be that in a certain project period (e.g.: one year) the total working hours of employees should greater than the total demanding working hour of all the projects.

\section{The Follow-Ups}

The HR planning model for talent dispatch agency proposed in this article can basically solve the problem in the planning stage of a dispatch agency, such as the number of employees to dispatch; whether recruitment is needed, if so, how many should recruit; whether an overtime is needed, if so, how many time should plan and make sure the cost being as little as possible. This article also proposed a dispatch model and it is to determine how to dispatch the labors to make an optimization.

Follow-ups: The model needs a lot of improvements to deal with various changes in practice. Due to the limit of time, this article didn't add some factors in the model. A typical point is the successive of job kinds that one job kind in a project could not start until another job was finished. This may lead to a situation of being more costly that the accomplish time shortened and the number of dispatch employees increased. Another point is in the dispatch planning model it is necessary to input a "penalty factor" to resolve the labor shrinking situation such as leave, make hay and other uncertainties. And in recruitment it should put a dynamic model to take the resignation into account.

\section{References}

[1] C. Pei and F. Shih-Chieh, "Can agency theory disclose organizational commitment? Exploring employees and agency workers", Technology Management Conference (ITMC), 2011 IEEE International, (2011), pp. $100-102$.

[2] W. Zheng, "A Research on the History, Present Conditions and Future Trends of Human Dispatch Business in Japan”, ICEEM 2012: 2012 2nd International Conference on Economic, Education and Management, Shanghai, vol. 2, (2012), pp. 218-222.

[3] X. Bi, M. Yu and F. Zhang, "Research on Customer Satisfaction Evaluation Index System of Manpower Dispatch Industry”, 2010 International Conference E-Business and E-Government (ICEE), pp. 991-994.

[4] Z. Guo, "Theory and practice analysis on labor relations of Labor dispatching system", Decision Making Cons, vol. 1, (2010).

[5] C. He, "Research on labor dispatching system", Legal System Soc, vol. 2.

[6] A. Huang and W. Xu, "Analysis of Labor dispatching employment", Journal of south China University of technology, vol. 12, (2009).

[7] W. Huang, "Risk and Prevention of labor dispatching in enterprise", Journal of Guangdong national technical college, vol. 3, (2010). 
[8] Y. Lin, "Research on labor dispatching legislation based on labor contract law", Management and Observation, vol. $6,(\mathbf{2 0 1 0})$.

[9] L. Xie, "Full guide of the labor contract", Full Guide Labor Con. Legal Press, Beijing, (2007).

[10] S. Zhou and X. Gu, "Legal regulations of labor dispatching", Public Business, vol. 1, (2010).

[11] C. Miao and Y. Qi, "On the Regulation of the Labor Dispatch", 2011 International Conference on Social Sciences and Society (ICSSS 2011), vol. 3, (2011), pp. 305-308.

[12] Z. Xu and X. Cai, "Labor Dispatching Play Functions", Economic Forum, vol. 5, (2004).

[13] R. Wang, "The Status and Problems of Software Developer Labor Dispatching", Capital University of Economics, (2010).

[14] D. Sheigren, "Why HR Outsourcing Continued to Expand", Employment Relations Today, vol. 2, (2004), pp. 56-60.

[15] X. Li, "Study of Human Resource Planning and Software System (HRPS)”, Nankai University, (2003). 